\title{
A Comparative Study of DG Impacts on Power System Stability under Equal and Unequal Load Growth Scenarios
}

\author{
Kiran. R. Patil \\ Department of Electrical and Electronics \\ Engineering, \\ B.V.B College of Engineering \& \\ Technology, \\ HUBLI -580 031 (INDIA) \\ krpatil@kletech.ac.in
}

\author{
S.R. Karnik \\ Department of Electrical and Electronics \\ Engineering, \\ B.V.B College of Engineering \& \\ Technology, \\ HUBLI -580 031 (INDIA) \\ karniksr@yahoo.com
}

\author{
A.B. Raju \\ Department of Electrical and Electronics \\ Engineering, \\ B.V.B College of Engineering \& \\ Technology, \\ HUBLI -580 031 (INDIA) \\ a_b_raju@yahoo.co.in
}

\begin{abstract}
The distributed generation (DG) technology is developed to meet the increasing load demand at a load centre by exploring locally available energy sources, including renewables. Although DG technology offers many technical and economic benefits, certain issues need further research. The impact of DG penetration on the system's stability is one such issue that requires significant attention in power system research. This study investigates the impact of DG penetration on the system's small-signal and transient stability under equal and unequal load growth scenarios. The unequal load growth condition is simulated by employing an orthogonal array (OA), and the impact of DG penetration on small-signal stability is analyzed through critical eigenvalues while time-domain indicators were employed to analyze transient stability. The importance of unequal load growth conditions while evaluating the impact of DG penetration on stability is demonstrated on a 3 generators, 9 bus WSCC power system.
\end{abstract}

Keywords-Critical damping ratio, Distributed generation, Penetration level, Power system stability, Time-domain indicators, Unequal load growth.

\section{INTRODUCTION}

The concept of meeting increased power demand at a load centre by a distributed generation (DG) source employing locally available energy resources has recently attained significant attention in power system research. Environmental, regulatory, and commercial factors contributed in the development of DG technology. The main idea of DG is to explore available energy resources and generate electricity at sites close to end-user locations $[1,2]$.

The main objective in the development of DG technologies is to utilize the energy efficiently with reduced losses, reduced operation and maintenance cost, improved power quality, high reliability, ease of integration, and low carbon emissions [3]. Thus, it is expected that DG technologies will have a significant contribution to the growth of power systems in the near future $[1,3]$. However, although DG offers many benefits, certain issues that require further research [4-10].

There are several issues of power system operation with DG sources; stability is one such important issue that requires much consideration in power system research [11]. Earlier studies indicated that when applied in small amounts, DG offers major benefits $[12,13]$. On the other hand, few recent studies have shown that increased DG penetration has adverse effects on power system stability. High DG penetration can cause voltage instability and a significant reduction in transient stability margin [6]. A summary of the DG and its penetration on the stability of the stand-alone, grid-connected, and hybrid power systems is available in [14].

Most of the earlier studies focussed mainly on the impact of DG penetration on voltage and transient stabilities. The literature review indicated that the DG impact analysis on transient stability was based on time-domain indicators. However, it is important to know how small-signal stability is affected by DG penetration.

In most of the earlier reported investigations, a one-DG source-at-a-time (ODGST) approach was employed to determine the DG impact on transient stability [14, 15]. In the ODGST approach, by connecting the same technology DGs at all load centres, the DG penetration is increased in steps to evaluate the impact on stability. However, different technology DGs are employed in different load centres based on the availability of energy resource at a particular load centre. Furthermore, equal load demand growth was assumed at all DG-connected load centres in the analysis. However, in reality, the rate of load demand growth is not necessarily the same at all DG-connected load centres. Further investigations are, therefore necessary to determine the effects of equal and unequal load demand growth conditions on stability under various levels of DG penetrations.

This article presents a study on the impact of rotating type DGs on stability under equal and unequal load demand growth scenarios. The small-signal stability is analyzed by evaluating the critical damping ratio, while time-domain indicators are employed to analyze the transient performance. Further, analysis of variance (ANOVA) test is employed to determine the importance of DG sources.

\section{POWER SYSTEM MODELING}

\section{A. Distributed Generation System Model and Penetration Level}

Fig. 1 illustrates the distributed generation model employed in the present study. A DG is directly interfaced at a load bus, and its active power generation is set equal to increased load demand at that load bus [6, 14]. This DG power setting ensures that the power generation schedule of 
main synchronous generators (SG) and the power flow patterns in the transmission network remain unchanged under steady-state conditions. This distributed generation model is simple and has all the features required to study the impact of DG penetration on main synchronous generators.

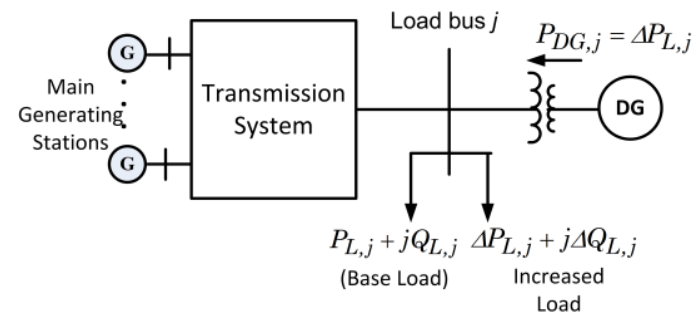

Fig. 1. Distributed System Model

The increase in load active power is balanced by the active power generation of the DG connected at that particular load bus, as illustrated in Fig. 1. The DG penetration level (DGPL) is evaluated as a ratio of the total active DG power generation and the total load demand of the system and is given by:

$$
\% D G P L=\frac{\sum_{j} P_{D G, j}}{P_{L}+\Delta P_{L, j}} \times 100
$$

Where, $P_{\mathrm{L}}$ is the base case total active power demand of the system.

The fraction of load power change at a load bus- $j$ is defined as:

$$
\beta_{j}=\frac{\Delta P_{L, j}}{P_{L, j}}
$$

The active power generation of DG at load bus-j is fixed as:

$$
P_{D G, j}=\Delta P_{L, j}=\beta_{j} P_{L, j}
$$

\section{B. Distributed Generation Models}

In the present study, fixed-speed wind turbine generator (WTG) and SG interfaced DGs (micro turbine generator, MTG, diesel turbine generator, DTG) are considered. In deriving the models, the following assumptions are made:

- All SGs are represented by a $4^{\text {th }}$ order d-q axis model equipped with IEEE type-ST1 fast-acting static exciters (modeled by a single time constant AVR with gain $K_{\mathrm{A}}=200$ and time constant $T_{\mathrm{A}}=0.05 \mathrm{sec}$ ).

- The main SGs are equipped with two-stage fixed structure speed based lag-lead type power system stabilizers (PSS)

- The main SGs are driven by a simplified version of steam turbines [16].

- All loads are modeled as constant impedances.

The SG interfaced micro turbine (MTG) employed in the present study is based on the gas turbine model adapted from [17]. The MTG model mainly consists of turbine components in addition to a compressor and the combustor [18]. A diesel turbine governor model consists of an engine, an electric control box, and an actuator interfaced with an SG [17]. In the present study, the Type-A WTG model comprising a fixed- speed wind turbine and a direct grid-connected squirrel-cage induction generator (SCIG) is employed. A two-mass drive train representation is used in the WTG model. The WTG model assumes very fast stator transients as compared with the rotor ones. Hence, the stator flux transients are neglected in the voltage equations while deriving the fixed speed IG model suitable for stability studies [17].

The transfer function models of MTG, DTG, and the model parameters are provided in Appendix-A.

\section{Problem Formulation}

The impact of DG penetration on small-stability is investigated using a critical damping ratio ( $\zeta \mathrm{cr}$ ). The linearized state-space model of the system and interfaced DGs, assuming constant inputs, is given by:

$$
\Delta \stackrel{\bullet}{X}=A \Delta X
$$

Where $\boldsymbol{A}$ is the state matrix, and $\Delta \boldsymbol{X}$ is the vector of state variables. For specified operating conditions and system parameters, eigenvalues of the entire system are determined from the state matrix $\boldsymbol{A}$. The damping ratio associated with an oscillating mode eigenvalue $\lambda_{i}=\alpha_{i} \pm j \omega_{d, i}$ is given as:

$$
\zeta_{i}=\frac{-\alpha_{i}}{\sqrt{\alpha_{i}^{2}+\omega_{d, i}^{2}}}
$$

The critical damping ratio is

$$
\zeta_{\mathrm{cr}}=\operatorname{Min}[\zeta ; \zeta \in \text { oscillating modes }]
$$

In the present work, the linearized state-space model is formulated in the SIMULINK/MATLAB environment [19]. In this approach, the solution of all state equations of various power system components is formulated by developing SIMULINK models. In addition, a non-iterative AC network solution is developed to update the non-state variables of the system during the simulation process.

All loads are represented by equivalent shunt admittances, and the bus admittance matrix $Y_{B U S}$ is then updated to consider these equivalent load admittances. Hence, the current injection at load buses will be zero. The non-iterative network voltage solution can be derived from the reduced network (retaining only the generators), and is given as:

$$
V=\left[T-Z_{M} T Y_{N}\right]^{-1} E
$$

Where $Y_{N}$ is $\left(2 n_{g} \mathrm{x} 2 n_{g}\right)$ matrix of real and imaginary part of $Y_{B U S}$ elements, $n_{g}$ is the total number of generators; $T$ is the block diagonal transformation matrix. For $i^{\text {th }} S G$, $T_{i}=\left[\begin{array}{cc}\operatorname{Cos} \delta_{i} & \operatorname{Sin} \delta_{i} \\ -\operatorname{Sin} \delta_{i} & \operatorname{Cos} \delta_{i}\end{array}\right]$ and $\delta_{\mathrm{i}}=0$ for SCIG. $Z_{M}$ is the block diagonal matrix of machine impedance, where

$$
\begin{aligned}
& z_{m, i}=\left[\begin{array}{cc}
-R_{a, i} & x_{d, i}^{\prime} \\
-x_{q, i}^{\prime} & -R_{a, i}
\end{array}\right] \text { for the } i^{\text {th }} \text { SG and } \\
& z_{m, i}=\left[\begin{array}{cc}
-R_{S, i} & X_{S, i}^{\prime} \\
-X_{S, i}^{\prime} & -R_{S, i}
\end{array}\right] \text { for the } i^{\text {th }} \text { SCIG. }
\end{aligned}
$$




$$
E=\left[E_{q 1}{ }^{\prime} E_{d 1}, \ldots \ldots E_{q m}{ }^{\prime} E_{d m}\right]^{\mathrm{t}}
$$

A MATLAB function is developed to implement the AC network solution and embedded in the SIMULINK model. The main advantage of the SIMULINK power system model is that both state matrix and time-domain simulation results can be obtained from the same SIMULINK model.

\section{CASE STUDY AND SIMULATION RESULTS}

\section{A. Test System and Simulation Setup}

In the present study, a 9 bus, 3 generators WSCC benchmark power system is employed. All machine and line data are taken from [20]. The system consists of three load centres, and the total load demand is $530 \mathrm{MW}$ and 200 MVAr. MTG, DTG, and WTG are interfaced at load buses 5, 6 , and 8 , respectively, via a transformer of $(0+\mathrm{j} 0.056) \mathrm{pu}$ impedance.

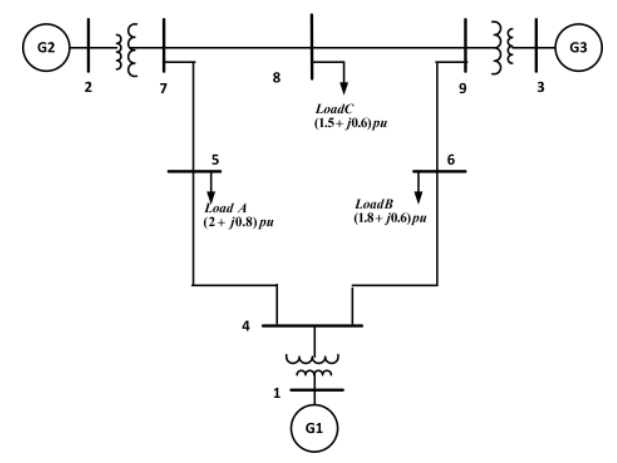

Fig. 2. WSCC Test power system

The active and reactive power at load buses 5,6 , and 8 is increased, and the active power generation of corresponding DGs is set as per Eq.(3). At any load bus, the maximum load increase is assumed as $50 \%$ of the base-load $\left(\beta_{j}=0.5\right)$ at that bus. Therefore, as per the base-case load data, the maximum DG penetration can be calculated as $33.33 \%$.

The unequal load growth scenario is simulated by assuming 5 discrete levels of a fraction of load change in the range [0.0:0.5] as summarized in Table I.

TABLE I. LEVELS OF A FRACTION OF LOAD CHANGES

\begin{tabular}{|c|c|c|c|c|c|}
\hline \multirow{2}{*}{$B_{j}$} & \multicolumn{5}{|c|}{ Levels of fraction of a load change } \\
\cline { 2 - 6 } & Level-1 & Level-2 & Level-3 & Level-4 & Level-5 \\
\hline$\beta_{\text {MTG }}$ & 0.02 & 0.14 & 0.26 & 0.38 & 0.5 \\
\hline$\beta_{\text {DTG }}$ & 0.02 & 0.14 & 0.26 & 0.38 & 0.5 \\
\hline$\beta_{\text {WTG }}$ & 0.02 & 0.14 & 0.26 & 0.38 & 0.5 \\
\hline
\end{tabular}

The simulation of unequal load growth scenario requires all 125 combinations of different levels of $\beta_{j}$ as per full factorial design (FFD), which is time-consuming. However, this problem can be overcome by employing an orthogonal array (OA) with only a few combinations of $\beta_{j}$ levels. For 3 DG groups, each defined with 5 discrete levels of $\beta$ values, the minimum number of entries required in an $\mathrm{OA}$ is given as:

$$
N_{\text {min }}=(L-1) F+1
$$

In Eq. (8), $L$ is the number of levels $(=5)$, and $F$ is the number of control factors $(=3)$. Therefore, an appropriate 5level OA is to be selected such that the number of entries $N>N_{\min }=13$. Hence $L_{25}$ or $5^{3}$ OA is selected with 25 entries. Table II summarizes the various combinations of $\beta_{\mathrm{MTG}}, \beta_{\mathrm{DTG}}$, and $\beta_{\text {WTG }}$ levels as per $L_{25}$ OA and the corresponding DGPL levels.

\begin{tabular}{|c|c|c|c|c|}
\hline \multirow{2}{*}{$\begin{array}{r}\text { En } \\
\text { try No }\end{array}$} & \multicolumn{4}{|c|}{ Fraction of load changes } \\
\hline & $\beta_{\mathrm{MTG}}$ & $\beta_{\text {DTG }}$ & $\beta_{\mathrm{WTG}}$ & DGPL\% \\
\hline 1 & 0.02 & 0.02 & 0.02 & 1.9608 \\
\hline 2 & 0.02 & 0.14 & 0.14 & 8.6522 \\
\hline 3 & 0.14 & 0.02 & 0.26 & 14.4885 \\
\hline 4 & 0.02 & 0.26 & 0.26 & 19.6239 \\
\hline 5 & 0.26 & 0.14 & 0.02 & 24.1774 \\
\hline 6 & 0.14 & 0.14 & 0.38 & 9.0285 \\
\hline 7 & 0.14 & 0.5 & 0.14 & 14.8184 \\
\hline 8 & 0.14 & 0.38 & 0.02 & 22.7180 \\
\hline 9 & 0.02 & 0.38 & 0.38 & 24.4368 \\
\hline 10 & 0.38 & 0.02 & 0.14 & 18.5868 \\
\hline 11 & 0.26 & 0.02 & 0.5 & 15.1457 \\
\hline 12 & 0.26 & 0.38 & 0.26 & 20.2048 \\
\hline 13 & 0.26 & 0.26 & 0.14 & 24.6945 \\
\hline 14 & 0.14 & 0.26 & 0.5 & 18.8858 \\
\hline 15 & 0.5 & 0.26 & 0.02 & 23.5209 \\
\hline 16 & 0.38 & 0.26 & 0.38 & 20.4920 \\
\hline 17 & 0.02 & 0.5 & 0.5 & 24.9504 \\
\hline 18 & 0.38 & 0.14 & 0.26 & 19.1827 \\
\hline 19 & 0.38 & 0.5 & 0.02 & 23.7849 \\
\hline 20 & 0.26 & 0.5 & 0.38 & 27.8912 \\
\hline 21 & 0.5 & 0.14 & 0.5 & 25.2046 \\
\hline 22 & 0.5 & 0.02 & 0.38 & 19.4774 \\
\hline 23 & 0.5 & 0.38 & 0.14 & 24.0470 \\
\hline 24 & 0.38 & 0.38 & 0.5 & 28.1258 \\
\hline 25 & 0.5 & 0.5 & 0.26 & 31.7889 \\
\hline
\end{tabular}

TABLE II. $\quad$ L $25_{2}$ ORTHOGONAL ARRAY AND DG PENETRATION LEVELS

The important properties and advantages of $\mathrm{OA}$ are summarized below:

The columns of OA are mutually orthogonal and exhibit balancing properties. As seen from Table II, all combinations of factor levels occur in an equal number of times for any pair of columns. Because of this property, an OA defines an experimental region of factors to be studied.

OA exhibits fractional factorial characteristics. Moreover, the results obtained using OA are almost the same as that can be obtained from FFD. Hence the use of OA saves computational time significantly.

\section{Impact Study on Small-Signal Stability}

Critical eigenvalues under unequal load growth scenario (UELG) are computed as per the $L_{25}$ OA using the linearized state matrix $A$. For comparison purposes, for the same DG penetration levels as in Table II, critical eigenvalues are also computed under an equal load growth scenario (ELG). The value of $\beta_{j}$ for equal load growth is determined as: 


$$
\beta_{M T G}=\beta_{D T G}=\beta_{W T G}=\frac{D G P L}{1-D G P L}
$$

Fig. 3 depicts the comparison of $\zeta_{\mathrm{cr}}$ under ELG and UELG scenarios.

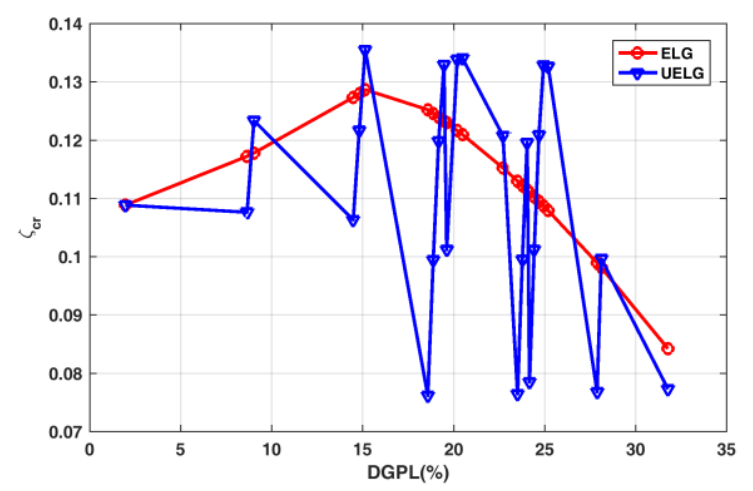

Fig. 3. Comparison of Critical damping ratio under equal and unequal load growth scenarios.

It is clear from Fig. 3 that the variations of $\zeta_{\mathrm{cr}}$ with DGPL under UELG are quite different than under ELG conditions. Up to $15 \%$ DGPL, $\zeta_{\text {cr }}$ show an increasing tendency and as DGPL increases beyond this, there is a sharp reduction in $\zeta_{\mathrm{cr}}$ values.

For the same DGPL, the $\zeta_{\text {cr }}$ value under UELG is significantly different than under ELG condition. The $\zeta_{\mathrm{cr}}$ value and hence the small-signal stability depend on the active power generation of DGs. For the same DGPL, DGs' active power generation settings are different under ELG and UELG conditions and hence affect the small-signal stability. It is worth noting here that for few combinations of $\beta$ values, unequal load growth conditions resulted in much higher values of $\zeta_{\text {cr }}$ as compared to equal load growth conditions.

ANOVA test was performed to determine the relative importance of each DG source and their interaction effects on the variance of $\zeta_{\text {cr }}$ values. ANOVA test is performed using the "anovan" routine available in the MATLAB toolbox, which gives the percentage contribution of each DG source (direct or main effects) and the contribution due to the interaction. The results of ANOVA are summarized in Table III.

TABLE III. ANOVA TEST RESULTS

\begin{tabular}{|c|c|}
\hline DG Source & \% Contribution \\
\hline Direct effect of MTG & 6.72 \\
\hline Direct effect of DTG & 86.75 \\
\hline Direct effect of WTG & 0.02 \\
\hline $\begin{array}{c}\text { Interaction between MTG and } \\
\text { DTG }\end{array}$ & 6.33 \\
\hline $\begin{array}{c}\text { Interaction between DTG and } \\
\text { WTG }\end{array}$ & 0.14 \\
\hline
\end{tabular}

The ANOVA test results indicate that the DTG alone contributes around $86.75 \%$ towards the variance of $\zeta_{\mathrm{cr}}$ values. There is a small interaction effect $(6.33 \%)$ between MTG and DTG, while all other interactions are negligible. The direct or main effect indicates the overall effect of each DG source alone to change the critical damping ratio, while the interaction effect indicates the mutual dependency of the two DG sources. The ANOVA test results are validated by the analysis of means (ANOM), as illustrated in Fig. 4.

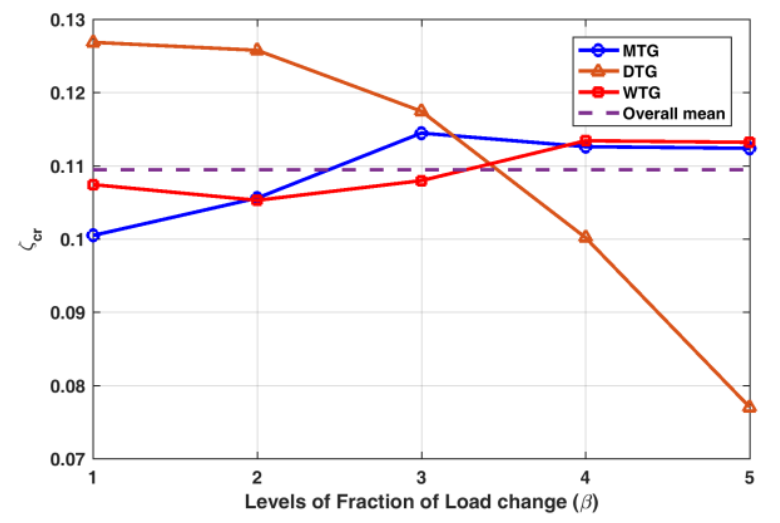

Fig. 4. Results of Analysis of means (ANOM)

In Fig. 4 , the overall mean value of $\zeta_{\text {cr }}(0.1095)$ is shown by dotted line. It is clear that a change in the level of $\beta$ of DTG results in large variations of mean $\zeta_{\text {cr }}$ around the overall mean and therefore contributes significantly towards the variance. Moreover, it is seen that the mean value of $\zeta_{\text {cr }}$ reduces sharply when the level of $\beta$ of DTG is increased. In the case of MTG, there is a slight increase in the mean value of $\zeta_{\mathrm{cr}}$ when $\beta$ increased up to level 3.

\section{B. Impact study on Transient Stability}

The comparison of relative slip deviation response $\left(S_{\mathrm{m}, 21}\right.$ and $S_{\mathrm{m}, 31}$ ) of main SG under ELG and UELG conditions and DGPL $=24.95 \%$ for $125 \mathrm{~ms}$ duration 3-phase self-clearing fault on bus 9 is depicted in Fig. 5. The corresponding transient response comparisons for MTG, DTG, and WTG for this fault are shown in Fig. 6. At DGPL $=24.95 \%$ the values of fraction of load changes for UELG are $\beta_{\mathrm{MTG}}=0.02, \beta_{\mathrm{DTG}}=0.5$, and $\beta_{\mathrm{WTG}}=0.5$ while, for ELG it is $\beta_{\mathrm{MTG}}=\beta_{\mathrm{DTG}}=\beta_{\mathrm{WTG}}=0.3325$.

It is seen from Fig. 5 and Fig.6 that the transient response of main SG and all DGs are more oscillatory under UELG as compared to ELG. Since under UELG condition, the DTG active power generation is set at maximum (0.5), the system's damping is very low, resulting in poor transient performance.

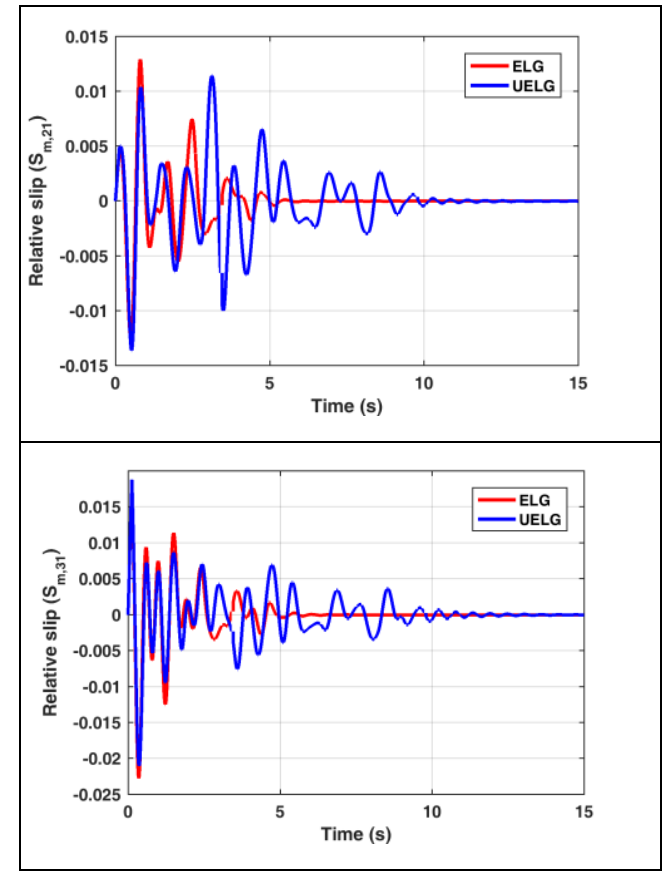

Fig. 5. Transient response comparison of main SG under ELG and UELG (DGPL $=24.95 \%)$ 
In order to quantify the impact of DGPL on system transient response under ELG and UELG, two time-domain indicators, namely maximum slip deviation (MSD) and settling (ST) are employed in this study. The MSD value indicates the worst value of maximum deviation among a group of responses. The settling time is measured using a $2 \%$ tolerance limit.

It is observed from Fig. 7 that the MSD values decrease as DGPL is increased in the case of main SG, MTG, and DTG, whereas MSD of WTG increases with an increase in DGPL. It is also seen that MSD values are significantly different under ELG and UELG scenarios. For few DGPL values, unequal load growth results in much larger MSD values than equal load growth condition.

From Fig. 8, it is seen that the settling time remains almost same for small DG penetration levels (DGPL<15\%). However, as DGPL increases beyond $15 \%$, the settling times of main SG and all DGs tend to increase, indicating growing oscillations. It is also observed that for the same DGPL, the settling time depends on the type of load growth, equal or unequal.

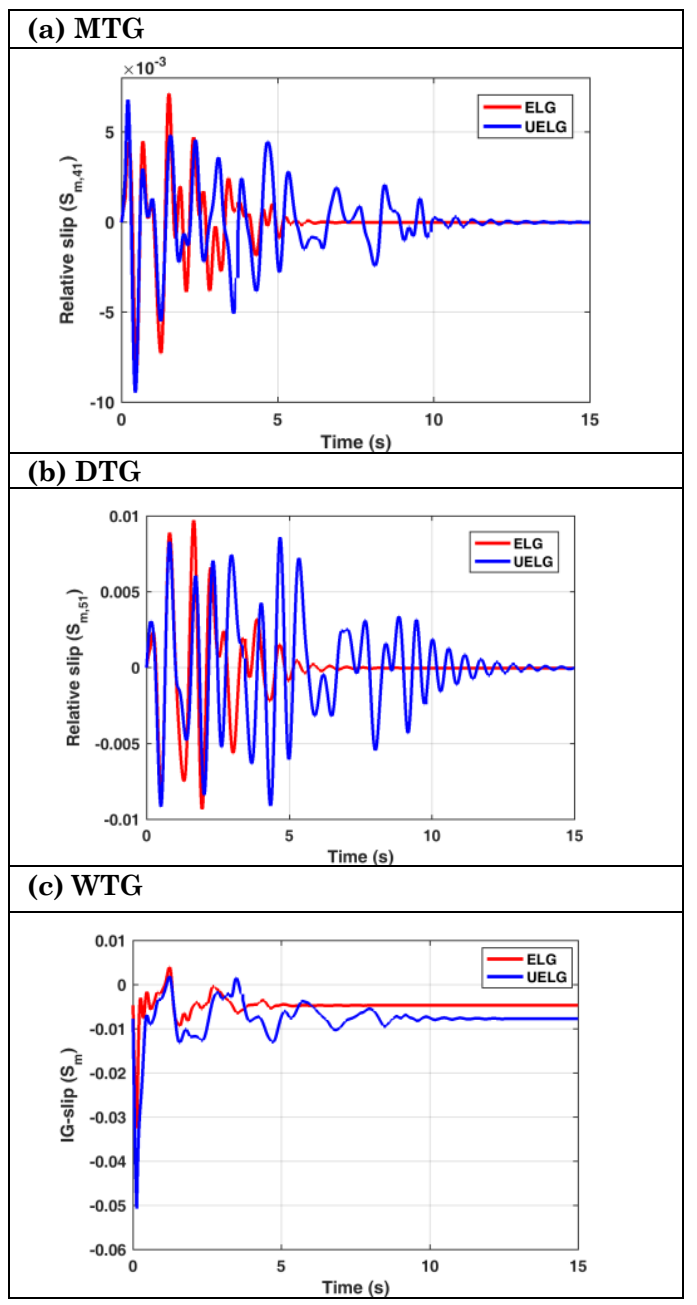

Fig. 6. Transient response comparison under ELG and UELG of (a) MTG (b) DTG (c) WTG (DGPL=24.95\%)
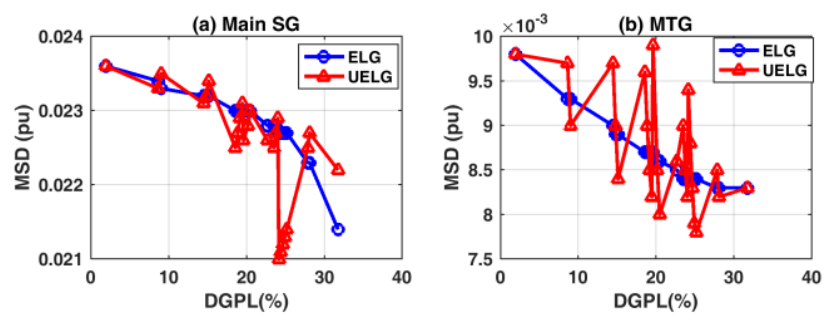

(c) DTG
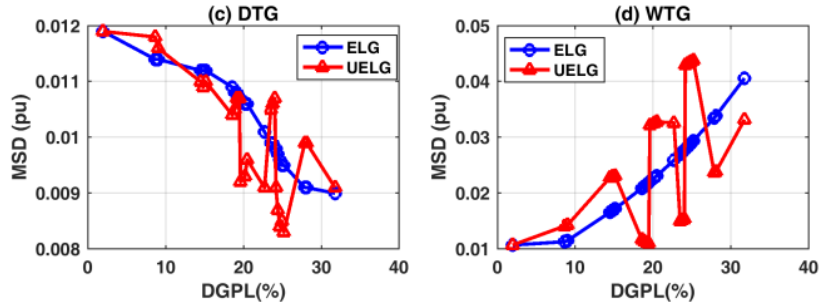

Fig. 7. Comparison of maximum slip deviation (MSD) under ELG and UELG conditions
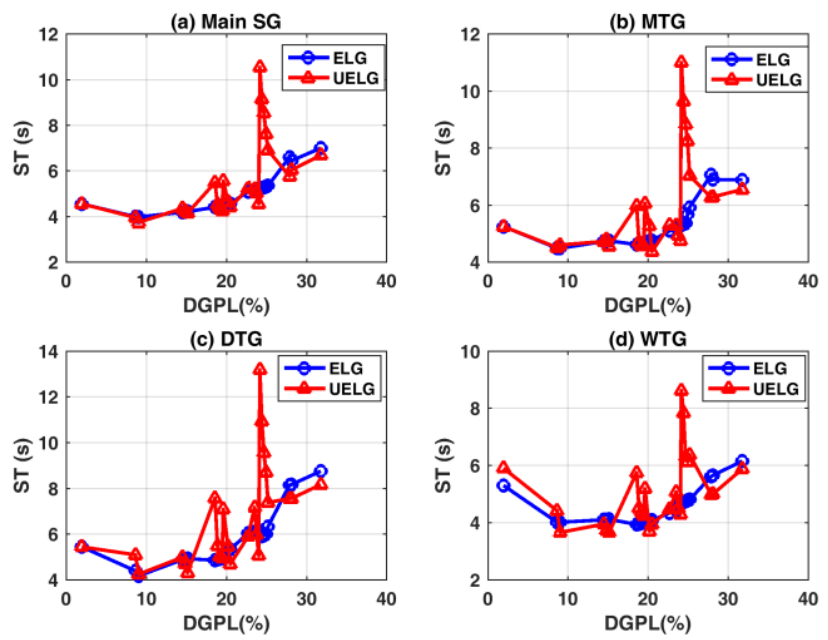

Fig. 8. Comparison of settling time (ST) under ELG and UELG conditions

From the above discussion, it is clear that the small-signal and transient stability of the power system depends not only on the DG penetration but also on the type of load growth scenario in the system. For the same DG penetration level, the stability performance may be significantly different under equal and unequal load growth scenarios. The definition of DG penetration as given by Eq. (1) does not reflect the type of load growth scenario. Further investigations are, therefore, necessary to arrive at a new definition of DG penetration that reflects both load growth and type of load growth, equal or unequal.

\section{CONCLUSIONS}

This paper provided a comprehensive analysis of the impact of DG on power system stability under equal and unequal load growth scenarios. SG interfaced DG sources (MTG and DTG) and fixed-speed WTG IS employed for this purpose. The study revealed that the power system exhibited different stability performances under equal and unequal load growth scenarios for the same DG penetration level. 


\section{APPENDIX-A}

\section{MODELS OF DIESEL AND MICRO TURBINES AND MODEL PARAMETERS}

(All data are in per-unit unless specified otherwise)

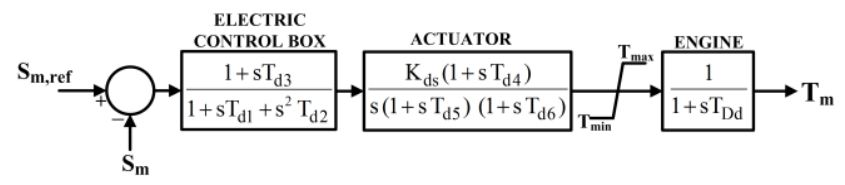

Fig. A1 Diesel turbine model

$T_{\mathrm{d} 1}=0.2 \mathrm{~s} ; \quad T_{\mathrm{d} 2}=0.02 \mathrm{~s} ; \quad T_{\mathrm{d} 3}=0.2 \mathrm{~s} ; \quad T_{\mathrm{d} 4}=0.25 \mathrm{~s} ; \quad T_{\mathrm{d} 5}=0.009 \mathrm{~s} ;$ $T_{\mathrm{d} 6}=0.0384 \mathrm{~s} ; T_{\mathrm{Dd}}=0.02 \mathrm{~s} ; K_{\mathrm{ds}}=30.0$.

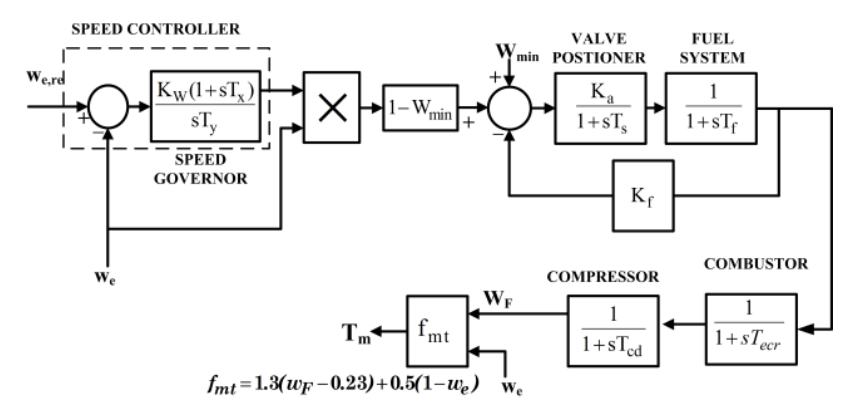

Fig. A2 Micro- turbine model

$K_{\mathrm{f}}=0.0 ; \quad K_{\mathrm{w}}=16.7 ; \quad K_{\mathrm{a}}=1.0 ; \quad T_{\mathrm{s}}=0.05 \mathrm{~s} ; \quad T_{\mathrm{x}}=0.0 ; \quad T \mathrm{y}=1.0 \mathrm{~s} ;$ $T_{\mathrm{f}}=0.4 \mathrm{~s} ; T_{\mathrm{cd}}=0.2 \mathrm{~s} ; T_{\mathrm{ecr}}=0.01 \mathrm{~s}$.

\section{APPENDIX-B}

\section{DYNAMIC MODEL EQUATIONS SYNCHRONOUS} AND INDUCTION GENERATORS

(a) Synchronous Generator

$$
\begin{aligned}
& \frac{d \delta}{d t}=\omega_{b} S_{m} \\
& \frac{d S_{m}}{d t}=\frac{1}{2 H}\left[T_{m}-T_{e}\right] \\
& \frac{d E_{q}^{\prime}}{d t}=\frac{1}{T_{d o}^{\prime}}\left[-E_{q}^{\prime}+\left(x_{d}-x_{d}^{\prime}\right) i_{d}+E_{f d}\right] \\
& \frac{d E_{q}^{\prime}}{d t}=\frac{1}{T_{q o}^{\prime}}\left[-E_{d}^{\prime}-\left(x q-x_{q}^{\prime}\right) i_{q}\right] \\
& \frac{d E_{f d}}{d t}=\frac{1}{T_{A}}\left[K_{A}\left(V_{r e f}-V_{t}+V_{p s s}\right)-E_{f d}\right]
\end{aligned}
$$

(b) Induction Generator

$$
\begin{aligned}
& \frac{d \gamma}{d t}=2 \pi f\left[\omega_{m}-\frac{\omega_{G}}{N_{G}}\right. \\
& \frac{d \omega_{m}}{d t}=\frac{1}{2 H_{m}}\left[T_{a e}-K_{s} \gamma-D_{m} \omega_{m}\right] \\
& \frac{d \omega_{G}}{d t}=\frac{1}{2 H_{G}}\left[T_{m}-T_{e}-D_{G} \omega_{G}\right]
\end{aligned}
$$

$$
\begin{aligned}
& \frac{d E_{q}^{\prime}}{d t}=\frac{-1}{T_{0}^{\prime}}\left[E_{q}^{\prime}-\left(X_{s}-X_{s}^{\prime}\right) i_{d}\right]+S_{m} \omega_{s} E_{d}^{\prime} \\
& \frac{d E_{d}^{\prime}}{d t}=\frac{-1}{T_{0}^{\prime}}\left[E_{d}^{\prime}-\left(X_{S}-X_{s}^{\prime}\right) i_{q}\right]-S_{m} \omega_{s} E_{q}^{\prime}
\end{aligned}
$$

\section{ACKNOWLEDGEMENTS}

The authors would like to thank Principal, B.V. Bhoomaraddi College of Engineering \& Technology Hubballi and Vice Chancellor of K.L.E Technological University Hubblli for providing required facilities to carry out this work.

\section{REFERENCES}

[1] T S Basso, System Impacts from Interconnection of Distributed Resources: Current Status and Identification of Needs for Further Development, Technical Report, Golden , Colorado, Jan 2009, Available online: https://digital.library.unt.edu/ark:/67531/meta dc931435.

[2] Y.W.Liang, Z.J.Hu and Y.P.Chen, "A survey of Distributed Generation and its Applications in Power Systems", Power System Technology, vol.27, no. 12, pp. 71-76, 2003.

[3] J.A. Peças Lopes, N. Hatziargyriou, J. Mutale, P. Djapic, and N. Jenkins, "Integrating distributed generation into electric power systems: A review of drivers, challenges and opportunities," Electric Power Systems Research, vol. 77, no. 9, pp. 1189-1203, 2007.

[4] P. Chiradeja and R. Ramakumar, "An approach to quantify the technical benefits of distributed generation," IEEE Transactions on Energy Conversion, vol.19, pp. 764-773, December 2004.

[5] Reza M, J.G. Slootweg, P.H. Schavemaker, W.L. Kling and L. Vandersluis, "Investigating impacts of distributed generation on transmission system stability," Power Tech Conference Proceedings, Bologna, Italy, vol. 2, June 2003

[6] M. K. Donnelly, J. E. Dagle, D. J. Trudnowski and G. J. Rogers, "Impacts of the distributed utility on transmission system stability," IEEE Transactions on Power Systems, vol. 11, no. 2, pp. 741-746, May 1996.

[7] Ahmad Rezaee Jordehi, "Allocation of distributed generation units in electric power systems: A review,", Renewable and Sustainable Energy Reviews, vol. 56, pp. 893-905, 2016.

[8] Tao Sun, Zhe Chen and F. Blaabjerg, "Flicker study on variable speed wind turbines with doubly fed induction generators," IEEE Transactions on Energy Conversion, vol. 20, no. 4, pp. 896-905, Dec. 2005.

[9] Boutsika T.N, and Papathanassiou S.A. "Short-circuit calculations in networks with distributed generation," Electric Power Systems Research, vol. 78, no. 7, pp. 1181-1191, 2008.

[10] N. Hidayatullah, Z. Paracha and A. Kalam, "Impact of Distributed Generation on Smart Grid Transient Stability," Smart Grid and Renewable Energy, vol. 2, no. 2, pp. 99-109, 2011.

[11] A. M. Azmy and I. Erlich, "Impact of distributed generation on the stability of electrical power system," IEEE Power Engineering Society General Meeting, 2005, vol. 2, pp. 1056-1063, 2005.

[12] J.G. Slootweg and W.L. Kling, "Impacts of distributed generation on power system transient stability," IEEE Power Engineering Summer Meeting, vol. 2, Chicago, IL, USA, pp. 862-867, July 2002.

[13] P. K. Olulope, K. A. Folly, S. Chowdhury and S. P. Chowdhury, "Dynamic impact and assessment of stability of power systems with DG penetration: A review", 45th International Universities Power Engineering Conference UPEC2010, Cardiff, UK, pp. 1-6, 2010.

[14] M. Reza, M. Gibescu, P. H. Schavemaker, W. L. Kling and L. van der Sluis, "Transient stability impacts of a 'vertical-to-horizontal' transformation of power systems," 2005 IEEE Russia Power Tech, pp. $1-6,2005$.

[15] Davood Khani, Ahmad Sadeghi Yazdankhah and Hossein Madadi Kojabadi, "Impacts of distributed generations on power system transient and voltage stability," Electrical Power and Energy Systems, vol. 43, pp. 488-500, July 2012. 
[16] K. R Padiyar, Power system dynamics stability and control, Second Edition, BS Publications, Hyderabad, 2002.

[17] E. N. Azadani, C. Canizares and K. Bhattacharya, "Modeling and stability analysis of distributed generation," 2012 IEEE Power and Energy Society General Meeting, pp. 1-8, 2012.

[18] Sanjeev K Nayak, and D N Gaonkar, "Modeling and Performance Analysis of Microturbine Generation System in Grid
Connected/Islanding Mode," 2012 IEEE International Conference on Power Electronics, Drives and Energy Systems, Bengaluru, India, pp. 1-6. December 2012,

[19] Math Works Incorporation. MATLAB user manual version 7.1 R14. Natick,(MA): Math Works Incorporation; 2005

[20] R.W. Sauer and M.A. Pai, Power System Dynamics and Stability. Pearson Education:Singapore, 2003. 